\title{
Corrigendum: Confused Connections? Targeting White Matter to Address Treatment Resistant Schizophrenia
}

\author{
Candice E. Crocker ${ }^{1,2}$ and Philip G. Tibbo ${ }^{1 *}$ \\ ${ }^{1}$ Department of Psychiatry, Dalhousie University, Halifax, NS, Canada, ${ }^{2}$ Department of Diagnostic Imaging, Nova Scotia \\ Health Authority, Halifax, NS, Canada
}

Keywords: psychosis, white matter, treatment resistance, treatment refractory, schizophrenia, neuropharmacology, neuroimaging

\section{A Corrigendum on}

Confused Connections? Targeting White Matter to Address Treatment Resistant Schizophrenia by Crocker, C. E., and Tibbo, P. G. (2018). Front. Pharmacol. 9:1172. doi: 10.3389/fphar.2018.01172

In the original article, we neglected to include funding section with the funder Canadian Institutes of Health Research (CIHR), grant number 391348, awarded in February 2018, to PT and collaborators on the grant, Dr. Lena Palaniyappan, CC, Dr. Ali Khan, Dr. Jacob Cookey, and Dr. Sherry Stewart. The authors apologize for this error and state that this does not change the scientific conclusions of the article in any way.

In the original article Palaniyappan, personal comm. was not cited in the article. The citation has

OPEN ACCESS

Edited and reviewed by: Mirko Manchia,

Università degli studi di Cagliari, Italy

*Correspondence:

Philip G. Tibbo

Phil.Tibbo@nshealth.ca

Specialty section:

This article was submitted to

Neuropharmacology,

a section of the journal

Frontiers in Pharmacology

Received: 30 October 2018 Accepted: 16 November 2018 Published: 04 December 2018

Citation:

Crocker CE and Tibbo PG (2018)

Corrigendum: Confused

Connections? Targeting White Matter

to Address Treatment Resistant

Schizophrenia.

Front. Pharmacol. 9:1417.

doi: 10.3389/fphar.2018.01417 now been inserted in Pharmacological WM Targets in Treatment Resistant Schizophrenia: Human Studies, paragraphs 1 and 11 and should read:

Paragraph one:

Based on the literature reviewed here, there are WM deficits that correlate with treatment resistance in schizophrenia. While other mechanisms of pharmacoresistance are still possible for any particular patient, if we consider WM as a target for therapy, there are options that are in development for human use. In fact, myelin enhancing strategies have been under investigation in human subjects for many years as effective treatments for multiple sclerosis are sought. Thus, repurposing and investigating these approved therapeutics currently in use for other medical conditions for treatment resistant patients is a reasonable approach. More specifically, putative myelinenhancing therapies would be potential candidates for large-scale clinical trials in schizophrenia. These include myelin-enhancing agents such as n-3 PUFA (Chen et al., 2014), minocycline (Rodgers et al., 2013), clemastine (Liu et al., 2016), polyphenols (Ghaiad et al., 2017), and potential neuro/myeloreparative agents such as sulfasalazine (Kim et al., 2015), nano-curcumin (Mohajeri et al., 2015), stem cell enhancing therapies such as Gli-1 inhibitors (Samanta et al., 2015), immunodmodulators such as fingolimod [FTY720, approved for use in MS (Kipp and Amor, 2012)], olexosime (Magalon et al., 2016) and retinoid receptor activators such as pioglitazone (Natrajan et al., 2015; Palaniyappan, personal comm.) (Summarized in Figure 2 and Table 2).

Paragraph 11:

A number of these agents are suitable for drug repurposing and repositioning applications, which greatly enhances the lab-to-clinic transition (Ashburn and Thor, 2004). Repurposing RCTs are already underway for some of these agents [e.g., fingolimod (fingolimod in Schizophrenia clinicaltrials.gov)] and pioglitazone (Iranpour et al., 2016). Of these minocycline, which 
predominantly limits neuronal damage by promoting oligodendrocyte progenitor proliferation and preserving mature oligodendrocytes (Guimaraes et al., 2010; Schmitz et al., 2012; Ma et al., 2015; Scheuer et al., 2015), and pioglitazone which promotes antioxidant defense of oligodendrocytes (Bernardo et al., 2009) have already shown promise in treating psychosis (Chaudhry et al., 2012; Iranpour et al., 2016). Further

\section{REFERENCES}

Ashburn, T. T., and Thor, K. B. (2004). Drug repositioning: identifying and developing new uses for existing drugs. Nat. Rev. Drug Discov. 3, 673-683. doi: $10.1038 / \mathrm{nrd} 1468$

Bernardo, A., Bianchi, D., Magnaghi, V., and Minghetti, L. (2009). Peroxisome proliferator-activated receptor-gamma agonists promote differentiation and antioxidant defenses of oligodendrocyte progenitor cells. J. Neuropathol. Exp. Neurol. 68, 797-808. doi: 10.1097/NEN.0b013e3181a ba2c1

Chaudhry, I. B., Hallak, J., Husain, N., Minhas, F., Stirling, J., Richardson, P., et al. (2012). Minocycline benefits negative symptoms in early schizophrenia: a randomised double-blind placebo-controlled clinical trial in patients on standard treatment. J. Psychopharmacol. 26, 1185-1193. doi: $10.1177 / 0269881112444941$

Chen, S., Zhang, H., Pu, H., Wang, G., Li, W., Leak, R. K., et al. (2014). n-3 PUFA supplementation benefits microglial responses to myelin pathology. Sci. Rep. 4:7458. doi: $10.1038 /$ srep 07458

Ghaiad, H. R., Nooh, M. M., El-Sawalhi, M. M., and Shaheen, A. A. (2017). Resveratrol promotes remyelination in cuprizone model of multiple sclerosis: biochemical and histological study. Mol. Neurobiol. 54, 3219-3229. doi: 10.1007/s12035-016-9891-5

Guimaraes, J. S., Freire, M. A., Lima, R. R., Picanco-Diniz, C. W., Pereira, A., and Gomes-Leal, W. (2010). Minocycline treatment reduces white matter damage after excitotoxic striatal injury. Brain Res. 1329, 182-193. doi: 10.1016/j.brainres.2010.03.007

Iranpour, N., Zandifar, A., Farokhnia, M., Goguol, A., Yekehtaz, H., KhodaieArdakani, M. R., et al. (2016). The effects of pioglitazone adjuvant therapy on negative symptoms of patients with chronic schizophrenia: a doubleblind and placebo-controlled trial. Hum. Psychopharmacol. 31, 103-112. doi: 10.1002/hup.2517

Kim, S., Lee, Y. I., Chang, K. Y., Lee, D. W., Cho, S. C., Ha, Y. W., et al. (2015). Promotion of remyelination by sulfasalazine in a transgenic zebrafish model of demyelination. Mol. Cells 38, 1013-1021. doi: 10.14348/molcells. 2015.0246

Kipp, M., and Amor, S. (2012). Fty720 on the way from the base camp to the summit of the mountain: relevance for remyelination. Mult. Scler. 18, 258-263. doi: 10.1177/13524585124 38723

Liu, J., Dupree, J. L., Gacias, M., Frawley, R., Sikder, T., Naik, P., et al. (2016). Clemastine enhances myelination in the prefrontal cortex and rescues behavioral changes in socially isolated mice. J. Neurosci. 36, 957-962. doi: 10.1523/JNEUROSCI.3608-15.2016 work is needed to see if an association exists between extensive WM changes and pharmacoresistance, but if it does then these individuals can be specifically targeted for clinical trials of myeloprotection (Palaniyappan, personal comm.).

The authors apologize for these errors and state that this does not change the scientific conclusions of the article in any way. The original article has been updated.

Ma, J., Zhang, J., Hou, W. W., Wu, X. H., Liao, R. J., Chen, Y., et al. (2015). Early treatment of minocycline alleviates white matter and cognitive impairments after chronic cerebral hypoperfusion. Sci. Rep. 5:12079. doi: 10.1038/srep 12079

Magalon, K., Le Grand, M., El Waly, B., Moulis, M., Pruss, R., Bordet, T., et al. (2016). Olesoxime favors oligodendrocyte differentiation through a functional interplay between mitochondria and microtubules. Neuropharmacology 111, 293-303. doi: 10.1016/j.neuropharm.2016.09.009

Mohajeri, M., Sadeghizadeh, M., Najafi, F., and Javan, M. (2015). Polymerized nano-curcumin attenuates neurological symptoms in eae model of multiple sclerosis through down regulation of inflammatory and oxidative processes and enhancing neuroprotection and myelin repair. Neuropharmacology 99, 156-167. doi: 10.1016/j.neuropharm.2015.07.013

Natrajan, M. S., Komori, M., Kosa, P., Johnson, K. R., Wu, T., Franklin, R. J., et al. (2015). Pioglitazone regulates myelin phagocytosis and multiple sclerosis monocytes. Ann Clin Transl Neurol. 2, 1071-1084. doi: 10.1002/ acn 3.260

Rodgers, J. M., Robinson, A. P., and Miller, S. D. (2013). Strategies for protecting oligodendrocytes and enhancing remyelination in multiple sclerosis. Discov. Med. 16, 53-63.

Samanta, J., Grund, E. M., Silva, H. M., Lafaille, J. J., Fishell, G., and Salzer, J. L. (2015). Inhibition of Gli1 mobilizes endogenous neural stem cells for remyelination. Nature 526, 448-452. doi: 10.1038/nature 14957

Scheuer, T., Brockmoller, V., Blanco Knowlton, M., Weitkamp, J. H., Ruhwedel, T., Mueller, S., et al. (2015). Oligodendroglial maldevelopment in the cerebellum after postnatal hyperoxia and its prevention by minocycline. Glia 63, 1825-1839. doi: 10.1002/glia.22847

Schmitz, T., Endesfelder, S., Chew, L. J., Zaak, I., and Buhrer, C. (2012). Minocycline protects oligodendroglial precursor cells against injury caused by oxygen-glucose deprivation. J. Neurosci. Res. 90, 933-944. doi: $10.1002 /$ jnr.22824

Conflict of Interest Statement: The authors declare that the research was conducted in the absence of any commercial or financial relationships that could be construed as a potential conflict of interest.

Copyright (c) 2018 Crocker and Tibbo. This is an open-access article distributed under the terms of the Creative Commons Attribution License (CC BY). The use, distribution or reproduction in other forums is permitted, provided the original author(s) and the copyright owner(s) are credited and that the original publication in this journal is cited, in accordance with accepted academic practice. No use, distribution or reproduction is permitted which does not comply with these terms. 